\title{
Childhood Embryonal Tumor with Multilayered Rosettes, C19MC-Altered
}

National Cancer Institute

\section{Source}

National Cancer Institute. Childhood Embryonal T umor with Multilayered Rosettes, C19MC-Altered. NCI Thesaurus. Code C115203.

An embryonal tumor with multilayered rosettes, C19MC-altered that occurs during childhood. 